\title{
Investigation and Countermeasures of Mild Social Phobia of College Students
}

\author{
Lu Wang ${ }^{1, *}$ Yihan $\mathrm{Yu}^{1}$ Yujia Zhai $^{1}$ \\ ${ }^{1}$ College of Arts and Sciences, Shanghai Polytechnic University, Shanghai 201209, China \\ *Corresponding author. Email:15658908@qq.com
}

\begin{abstract}
At present, the slight social fear of college students in interpersonal communication is more common, which affects and restricts the health and social interaction of college students to a certain extent. This article takes the mild social phobia in college students' interpersonal communication as the starting point. Based on questionnaire surveys and interviews, this article analyzes the causes of mild social phobia in college students, explores ways to alleviate social phobia, and provides countermeasures and suggestions on how to strengthen the psychological health of college students and strengthen their social core thinking.
\end{abstract}

Keywords: College students, Interpersonal communication, Mild social phobia.

\section{INTRODUCTION}

Social phobia (SP) is called social anxiety disorder. It is an excessive situational fear, that is, individuals are worried about being scrutinized and over-concerned in public performances and social situations, and they are afraid that they will be embarrassed and behave in embarrassment. For example, they are scared of speaking in public places; they have fear of eating in public places, and using public facilities, etc. And the fear response will cause the instinct to avoid these occasions, or feel extreme tension and discomfort in these occasions. [1] Adolescent college students value their own image extremely. They hope that they can appear in the public view with a satisfactory image and leave a good impression or desire to be recognized. Therefore, this kind of excessive expectations for interpersonal communication makes them often feel at a loss in their interactions, they will have a situation where their words are not in coherent, and some symptoms such as rapid heartbeat and shortness of breath may appear in the severe cases, which may cause a psychological burden and cause anxiety or

*Project: This article is related to the research results of the Shanghai Polytechnic University's 2021 trade union theory research and survey research project "The Realistic Path Research of University Trade Unions Helping the Growth of Young Teachers"; this article is the related research results of the 2021 ideological and political-navigation course "Management" of Shanghai Polytechnic University (JG2020-210). fear to a certain extent. The college level is a high incidence of (mild) social phobia, and about $80 \%$ of social phobia occurs before the age of 20 . If it is not adjusted in time, the "symptoms" may continue to later stages of life, which will have a negative impact on the individual's studies, career, interpersonal relationships, and family life.[2]

\section{INVESTIGATION ON MILD SOCIAL PHOBIA OF COLLEGE STUDENTS}

\subsection{Research Subjects}

The survey questionnaire was designed and distributed by the questionnaire star platform. A total of 225 sample data from Chinese and foreign university students were received. The valid questionnaire was 220 . The survey validity rate was $97.78 \%$, of which 80 answers were obtained overseas (data support from local college students during the overseas exchange in Finland), and 140 answers were obtained within China.

The proportion of female students in the survey is relatively high, the ratio of male to female is about 27:73; the students' grades are mainly distributed in the second and third years. 


\subsection{Research Goals}

The first is to find out the reasons for suffering from mild social phobia and effective solutions confirmed by practice.

The second is to try to analyze the characteristics and personality of people who are prone to mild social phobia.

The third is to summarize the specific manifestations, symptoms and judgment criteria of mild social phobia.

The forth is to obtain the opinions of mild social phobia among different college students.

The fifth is to explore generally applicable methods or suggestions to help people with mild social phobia to overcome their social phobia.

\subsection{Research Results}

\subsubsection{College Students Do Have Mild Social Phobia and Have a Certain Degree of Popularity}

Based on the results of questionnaires and interviews, it is not difficult for the researchers to conclude that most college students do have mild social phobia in their interpersonal relationships. Now the researchers take more than half of the data in the matrix scale question (marked) as an example to interpret. The meaning of the question in this question is the common phenomenon found and summarized in daily life among college students. The survey objects choose the degree of conformity according to their actual situation.

If the survey subject chooses "extremely consistent"/"basically consistent" in questions $1-10$, and "non-conforming" in questions 11-20, it can be inferred that the subject has a mild social phobia, and the specific manifestations and symptoms that are common among college students in interpersonal communication can be summarized: ("Table 1" and "Figure 1")

Table 1. Partial rectangular scale questions and data of the questionnaire

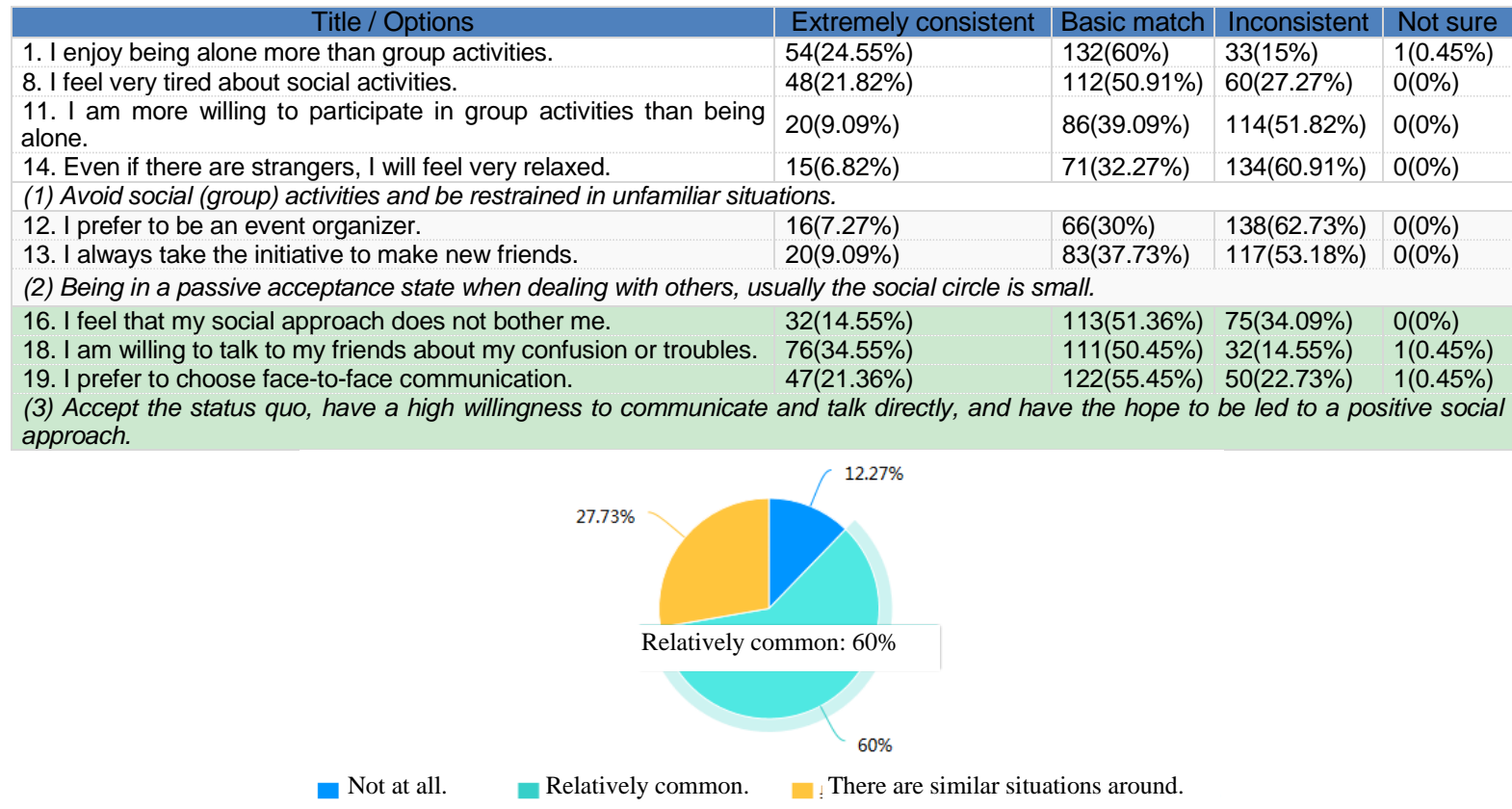

Figure 1 Question 5 "In your opinion, is mild social phobia common among college students?"

The data shows that $60 \%$ of college students believe that mild social phobia is relatively common, and $27.73 \%$ of college students believe that there is a similar situation around them. This shows that the mild social phobia of university colleges is worthy of attention. 


\subsubsection{College Students Are "Contradictory" in Interpersonal Communication and Have a Negative Attitude}

In the process of investigation, it is found that college students lack an objective analysis of interpersonal communication due to their immature world outlook, outlook on life, and values. Many difficulties are also caused by their bad psychology and negative mentality. In daily life, the researchers would more or less come into contact with people with ambivalence. This kind of ambivalence is generally reflected in two aspects: the first is that these people would like to speak up when helping others to solve the confusion, but if they are in a similar predicament, it is difficult to resolve themselves; the second is that they know their social barriers or social anxiety in interpersonal communication, but they are unwilling to improve. They use "this is also good", "we don't have to force ourselves to cater to others" and other relatively one-sided ideas to comfort themselves. But occasionally when there is too much negative emotion backlog, they reflect on whether it is correct to not improve the state of interpersonal communication, thus falling into a vicious circle.

\subsubsection{College Students Have Cognitive Biases Towards Mild Social Phobia}

From the interview process, it can be learnt that although some college students think that they have obstacles or anxiety in interpersonal communication, they cannot correctly analyze their indications. They only think that they are introverted, shy, do not like to interact with others, and do not realize that they have a tendency to develop mild social phobia. To a certain extent, it reflects that college students' cognition of their psychological health is not comprehensive. In the past learning and living environment, due to the heavy burden of academic pressure, they were over-focused on improving academic progress, and during the growth process, they neglected their psychological health because of the family atmosphere or the growth environment.

\section{ANALYSIS ON THE CAUSES OF MILD SOCIAL PHOBIA IN COLLEGE STUDENTS' INTERPERSONAL COMMUNICATION}

\subsection{Physical and Psychological Factors}

\subsubsection{Special Causes of Puberty}

Puberty makes people young and vigorous. The college students have strong self-esteem, are more sensitive to various reactions from the outside world, and care about others' evaluations and opinions about themselves. They are afraid that if they say something wrong, they will be rejected and despised by others, so they try to keep silent, which leads to the appearance of mild social phobia.[3]

\subsubsection{Excessive Self-confidence or Excessive Inferiority Caused by Lack of Objective Cognition and Evaluation of Oneself}

Too high evaluation of oneself will cause arrogance, leading to domineering, or disdain in the relationship; too low evaluation of oneself will cause low self-esteem, ashamed to get along with others, leading to a sense of fear in the relationship.

\subsubsection{Shyness and Solitary}

Specifically, it is manifested in the coy and unnatural movements of college students in interpersonal communication, and their volume of speech is low and small. They tend to constrain their words and deeds too much, but they cannot fully express their wishes and emotions, nor can they communicate smoothly with others, resulting in misunderstanding or uncomprehending of both parties. In this way, there is a barrier to others psychologically and behaviorally, and they would close themselves.

\subsection{External Environmental Factors}

\subsubsection{The Living Environment Is Closed and Single, Lacking the Experience and Skills of Interpersonal Communication}

Before entering the university, college students have tense learning tasks, rarely have the opportunity to develop their interpersonal skills, and their psychological endurance is not strong. But after entering the university, facing the many outstanding people who have passed the college entrance examination, their former advantages were not obvious among people, and there would be a feeling of loss and imbalance.[4] Therefore, they cannot correctly analyze and evaluate themselves and properly handle the relationship between 
classmates, which is very easy to produce confusion and illusions. Moreover, most contemporary college students are the only child in their families, more or less there are self-centered habits on them, and there are certain shortcomings in interpersonal communication skills.

\subsubsection{Social Alienation in the "Micro-era"}

Due to the rapid development of the mobile Internet, under various emerging communication methods and cultural forms, people have been imperceptibly introduced into the new social era the era of micro-communication, that is, the "microera".[5] However, virtual online communication has also replaced direct emotional communication between people, providing a place for college students to vent their bad emotions, seek spiritual sustenance, and escape from real life. This undoubtedly leads to the closure of college students in real-life communication and the decline of their interpersonal skills.[6]

\subsection{Cultural and Psychological Motivational Factors}

During the overseas exchanges, the researchers felt a sharp contrast in the same classroom: local students would always enthusiastically and actively "speak freely", discuss a certain point of view with the teacher, and keep asking or even asking if necessary; and the researchers are always more conservative and seem a little cautious. Because in fact, besides the researchers' own personality factors, "silence" and "no interaction with teachers" are commonplace in most classroom environments where many Chinese have been educated since childhood.

From the perspective of evolutionary psychology, people or animals have a more or less sense of territorial superiority, that is, people often show different mental outlooks and psychological expectations when communicating and interacting at home and away, When they hold the home court advantage, they would like to be more open naturally, being more relaxed and confident. In the away field, it is often caused by psychological disturbances, nervousness and other factors. People always feel that others will easily notice their own mistakes, leave a bad impression on others, and lose face. In fact, it is often an illusion caused by lack of (cultural) self-confidence.

\section{COUNTERMEASURES FOR MILD SOCIAL PHOBIA IN COLLEGE STUDENTS' INTERPERSONAL COMMUNICATION}

\subsection{Preventive Intervention}

\subsubsection{Learning the Knowledge of Interpersonal Communication and Improving the Behavior of Interpersonal Communication}

Subjectively, the students need to participate in the learning of some interpersonal communication courses, alleviate their fear of social interaction with an optimistic attitude through learning these courses, understand the purpose and meaning of interpersonal communication. [7] They can train themselves in interpersonal communication, learn to manage their emotions, improve their ability to regulate emotions, and increase their positive emotional experience.

Objectively speaking, the schools can hold lectures related to this to let college students understand the knowledge of interpersonal communication, organize more colorful campus activities to create a platform for exchanges between college students and provide a benign friendship environment for them to actively communicate, share experiences, make friends, and organize outing parties from time to time, which will help students with common characteristics to resonate, encourage each other, and help each other to alleviate their mild symptoms of social phobia.[8]

\subsubsection{Establishing Compulsory \\ Psychological Education Courses to \\ Strengthen Psychological Quality \\ Education}

At present, in the education system of major colleges and universities, in addition to psychologyrelated majors, psychological health education is mostly elective (expanding) courses, and the number of students who choose this type of course is not large, or they are simply to obtain high grades. Psychological health is the foundation for college students to have normal learning and social life, so schools should take the initiative to open and improve the psychological health education compulsory curriculum system to let every college student be able to learn and understand the common 
psychological obstacles or confusions of college students, so that they can better help themselves or the people around them face and solve various problems.[9]

At the same time, it can also be combined with professional training plans to carry out more practical courses on improving self-confidence. College students who have mild social fears are often afraid of failure or have had bad social experiences. Under the professional guidance of the course, the aim is to help them learn to recognize and encourage themselves, give themselves confidence, give play to their own advantages, and let themselves and others see their strengths, so as to make a difference to themselves.

\subsubsection{Strengthening the Construction of Psychological Quality and Cultivating Food Communication Quality}

Correct self-knowledge and self-acceptance are also an important part of the construction of college students' psychological quality. College students should let themselves learn to face the evaluation of the outside world squarely, and accept both praise and criticism with humility. It is necessary for them to understand how to recognize correct psychological counseling and positive psychological intervention, and not to always worry that asking for help will attract strange eyes from others.

Learning, training and improving mutual learning, unity and friendship, living in harmony in the practice of social interaction, achieving equality and respect for others, and achieving mutual respect are the foundations of friendship. It is necessary to cultivate the awareness of honesty among college students. "Sincerity makes the way to success smooth." When getting along with others, they must learn to be tolerant, accept the differences of the other side, and think in empathy from the perspective of the other side. It is believed that as long as they can make the above changes and adhere to the idea of "Don't do to others what you don't want others to do to you" and get along with others, their interpersonal relationships will get better and better.

\subsection{Targeted Intervention}

\subsubsection{Adjusting Cognitive Structure and Improving Personality Quality}

Cognitive therapy theory has such a description. The cognitive process is the mediator of emotion and behavior. Maladaptive behaviors and emotions are related to maladaptive cognition. College students with mild social phobia can find these maladaptive cognitions through counseling.

They must be clear about what they are afraid of and why they have such fear. If this kind of problem is caused by incorrect cognition of themselves and others, they can solve it by adjusting their cognition and increasing their confidence. For adaptive psychological training, the college students can first try to train with others around them. During the training process, they must continuously enhance their self-confidence, be brave in practice, and continuously improve their social self-confidence in practice.

\subsubsection{Increasing Social Exercise and Improving Communication Skills}

Improving actual communication skills plays a very important role in overcoming social fears. The motivation to change the way of interpersonal communication must come from one's own wishes, and social anxiety will become easier to eliminate in social situations over time.

College students participate in clubs or campus practical activities, or participate in some part-time and social practices. In such activities, they can make friends with like-minded students and exchange things they like. They can try to step out of the "comfort zone", try to meet new friends, and try to accept new possibilities, because action is the best way to resolve anxiety.

\subsubsection{Seeking Counseling from the Counseling Agencies}

College students who do have mild social phobia can seek help from professional psychological counseling agencies, usually group counseling or peer counseling, to actively increase their interpersonal interactions and improve their social fears.

Group psychological counseling is a form of psychological counseling and treatment that provides psychological help and guidance in a group situation. In the process of improving (mild) social phobia, group psychological counseling can better vent negative emotions, improve selfacceptance, increase the warm experience of interpersonal communication, adjust unreasonable 
cognition, and enhance communication confidence. Peer psychological distance is closer, which can create a good group psychological atmosphere, so that individuals can experience the warmth between people. Encouragement, acceptance, and respect among peers can well improve the psychological experience, and enhance self-acceptance and selfevaluation.

\subsubsection{The Construction of College Students' Interpersonal Relationship in the "Micro-era"}

Learning to balance the control of virtual social and real social is a compulsory course for college students in the "micro-era".[10] As the main users of mobile social applications, college students should reduce their reliance on electronic technology products such as mobile phones, and plan their time reasonably, avoiding over-focusing on wasting a lot of time and energy in mobile social applications and even causing procrastination. Contemporary college students should actively participate in real social interaction, give full play to their personal strengths, subjective initiative and creativity, and adapt to the real social environment. They need to adhere to true and effective communication methods, communicate effectively, and maintain a clear mind and judgment, and know how to be cautious and act cautiously. They also should increase their self-consciousness, strengthen their self-cultivation, and strive to create and realize their own value as much as possible. [11]

\section{CONCLUSION}

The mild social phobia in the interpersonal communication of college students has seriously affected the health of young students. Failure to solve it in time will affect study and life, and cause harm to physical and psychological health. The mild social phobia of college students in interpersonal communication is affected by physical and psychological factors, external environmental factors, and cultural and psychological motivational factors. Through preventive interventions and targeted interventions, it can help college students adjust their cognitive structure, improve their personality, increase social exercises, and improve their communication skills. Especially in the current Internet environment, it is more necessary to find the intersection and balance of virtual social and real social. [12]

\section{AUTHORS' CONTRIBUTIONS}

Lu Wang made the paper writing and revision, Yihan $\mathrm{Yu}$ made questionnaire surveys and data analysis, and Yujia Zhai made data analysis and paper editing.

\section{REFERENCES}

[1] Bi Li, Study of Interpersonal Relationship Barriers of Post-Secondary Students [J]. 2015(15): 136. (in Chinese)

[2] Cai Liqin, Yu Xiaoming, Du Yongwei, Interpersonal Relationships Construction of College Students in the Micro-era [J]. Heilongjiang Education(Theory \& Practice), 2020(02): 20-23. (in Chinese)

[3] Chen Gangling, Investigation and Guiding Strategies of College Students' Social Status in New Media [J]. Think Tank Era, 2019(24): 105-106. (in Chinese)

[4] Du Jiatong, Analysis on the Causes of the Obstacles in Interpersonal Communication among College Students and the Solutions [J]. Ability and Wisdom, 2016(09): 181. (in Chinese)

[5] Han Huimin, Wang Wenlin, Wu Yanmin, Chen Yunhui, Zhou Xinzhu, Research Progress of Social Phobia [J]. Journal of Qiqihar Medical College, 2010, 31(13): 21212122. (in Chinese)

[6] Lei Wenbin, Analysis and Countermeasures of College Students' Fear of Interpersonal Communication $[\mathrm{J}]$. Value Engineering, 2016, 35(32): 172-173. (in Chinese)

[7] Li Xinying, How Do College Students Overcome "Social Phobia" [J]. People's Tribune, 2018(36), 109. (in Chinese)

[8] Luo Zeru, Causes of College Students' Social Phobia and Intervention Policies [J]. 2014(09), 192-193. (in Chinese)

[9] Ren Yan, The Research on the Chinese Students' Amphibious Style of Using Social Media in the Context of Cultural Migration [D]. Shandong Unviersity, 2015. (in Chinese)

[10] Tao Jiashuo, Research on College Students' Interpersonal Communication Behavior in the New Media Era [J]. Think Tank Era, 2020(12): 78-79. (in Chinese) 
[11] Wang Qiuting, Yang Xuejun, On Social Alienation of College Students in the Era of Micro-communication [J]. Journal of Yanan Vocational \& Technical College, 2019, 33(03): 34-36. (in Chinese)

[12] Yu Lu, Research on Social Fear and Its Influencing Factors [J]. Chinese Out-of-school Education, 2019(09): 4-5. (in Chinese) 